\title{
Differential Ear Effects of Profound Unilateral Deafness on the Adult Human Central Auditory System
}

\author{
Deepak Khosla, ${ }^{1,4}$ Curtis W. Ponton, ${ }^{2,4}$ Jos J. Eggermont, ${ }^{3}$ Betty Kwong, ${ }^{4}$ \\ Manuel Don, ${ }^{4}$ and Juha-PekKa VAsama ${ }^{5}$ \\ ${ }^{1}$ HRL Laboratories, LLC, Malibu, CA 90265, USA \\ ${ }^{2}$ Neuroscan Labs, El Paso, TX 79912, USA \\ ${ }^{3}$ Department of Physiology and Biophysics and Department of Psychology, University of Calgary, \\ Calgary, Alberta, Canada T2N 1 N4 \\ ${ }^{4}$ Electrophysiology Department, House Ear Institute, Los Angeles, CA 90057, USA \\ ${ }^{5}$ Department of Otolaryngology, Helsinki University Central Hospital, Helsinki, Finland
}

Received: 8 April 2002; Accepted: 12 August 2002; Online publication: 15 January 2003

\section{ABSTRACT}

This study investigates the effects of profound acquired unilateral deafness on the adult human central auditory system by analyzing long-latency auditory evoked potentials (AEPs) with dipole source modeling methods. AEPs, elicited by clicks presented to the intact ear in 19 adult subjects with profound unilateral deafness and monaurally to each ear in eight adult normal-hearing controls, were recorded with a 31-channel system. The responses in the $70-210 \mathrm{~ms}$ time window, encompassing the $\mathrm{N}_{1 \mathrm{~b}} / \mathrm{P}_{2}$ and $\mathrm{Ta} / \mathrm{Tb}$ components of the AEPs, were modeled by a vertically and a laterally oriented dipole source in each hemisphere. Peak latencies and amplitudes of the major components of the dipole waveforms were measured in the hemispheres ipsilateral and contralateral to the stimulated ear. The normal-hearing subjects showed significant ipsilateral-contralateral latency and amplitude differences, with contralateral source activities that were typically larger and peaked earlier than the ipsilateral activities. In addition, the ipsilateralcontralateral amplitude differences from monaural presentation were similar for left and for right ear stimulation. For unilaterally deaf subjects, the previously reported reduction in ipsilateral-contralateral

Correspondence to: Curtis W. Ponton • Neuroscan Labs $• 5700$ Cromo Drive - El Paso, TX 79912. Telephone: (915) 845-5600; fax: (915) 845-2965; email: cponton@neuroscan.com amplitude differences based on scalp waveforms was also observed in the dipole source waveforms. However, analysis of the source dipole activity demonstrated that the reduced inter-hemispheric amplitude differences were ear dependent. Specifically, these changes were found only in those subjects affected by profound left ear unilateral deafness.

Keywords: Auditory evoked potentials (AEPs), dipoles, unilateral deafness, human, plasticity

\section{INTRODUCTION}

The plasticity of the mammalian auditory system after experimentally induced hearing loss has been demonstrated in several studies. This functional reorganization is evidenced mainly by two kinds of significant changes in the central auditory system activity: (1) reorganization of frequency maps in the auditory cortex, and (2) alterations in neural responses and binaural interactions at various levels in the auditory pathways. These changes have been demonstrated in both the developing (Harrison et al. 1991; Kitzes 1984; Reale et al. 1987; Eggermont and Komiya 2000) and the mature (Popelár et al. 1994; Rajan et al. 1993; Robertson and Irvine 1989) auditory system.

Restricted damage to the cochlea has been shown to alter the organization of contralateral cortical fre- 
quency maps in several species of mammals. For example, Reale et al. (1987) measured neural responses from the auditory cortex in cats reared with a neonatal unilateral cochlear ablation and reported modified tonotopic maps ipsilateral to the intact ear. Robertson and Irvine (1989) assessed the plasticity of cortical frequency organization in adult guinea pigs with induced unilateral partial deafness and found that the contralateral auditory cortex had an expanded representation of frequencies adjacent to the range damaged by the cochlear lesion. Similar reorganization of cortical frequency maps in the primary cortex contralateral to the partially lesioned cochlea has been reported in adult cats by Rajan et al. (1993).

Several studies have also demonstrated that unilateral hearing loss alters the neuronal activation and binaural interactions in the auditory pathways. For example, Kitzes at al. (1984) recorded responses from the inferior colliculus in gerbils with neonatal unilateral cochlear ablation and reported an increase in the excitatory responses on the ipsilateral side. In adult guinea pigs with induced hearing loss, neural responses recorded from both the auditory cortex and inferior colliculus ipsilateral to the intact ear show increased amplitudes and decreased thresholds (Popelár et al. 1994). Similarly, Reale et al. (1987) found reduced acoustic thresholds in the auditory cortex ipsilateral to the intact ear in cats with neonatal unilateral cochlear ablation.

Reorganization in adult humans following unilateral deafness has also been reported in a number of studies (Scheffler et al. 1998; Vasama and Mäkelä 1995, 1997; Vasama et al. 1995, 1998; Fujuki et al. 1998). For example, Scheffler et al. (1998) measured activity in the auditory cortex using functional magnetic resonance imaging (fMRI) and reported significantly smaller ipsilateral-contralateral activity differences in unilaterally deaf adults in comparison to normal-hearing adults. Using auditory evoked magnetic fields (AEFs), Vasama and Mäkelä (1995) reported that the stimulation of the intact ear after sudden sensorineural unilateral hearing loss generates AEFs with contributions from those cortical areas that play no role in the generation of AEFs in normal-hearing humans. These studies provide evidence of modified activation of the human central auditory pathways following unilateral hearing loss.

Ponton et al. (2001) also examined changes in cortical activation following unilateral deafness using evoked potentials. The results further characterized the changes from the pattern of asymmetrical (contralateral >ipsilateral amplitude) and asynchronous (contralateral earlier than ipsilateral) auditory system activation observed in normal-hearing subjects to a much more symmetrical and synchronous activation in the unilaterally deaf. Analyses of peak amplitude correlations suggested that the increased interhemispheric symmetry may be a consequence of gradual changes in the generators producing the $\mathrm{N}_{1}$ (approximately $100 \mathrm{~ms}$ peak latency) potential and that these changes continue for at least two years after the onset of hearing loss.

The present study was conducted to further assess modifications of central auditory system activation associated with profound unilateral deafness. The purpose of this analysis was to examine whether the side of deafness (left versus right ear) significantly affects the changes in cortical activation reported by Ponton et al. (2001). In a brain with symmetrical organization of function, it might reasonably be predicted that changes in cortical activation would be independent of the affected ear. However, it is well established that for more than $90 \%$ of the population, cortical processes of spoken language perception and production are asymmetrically represented in the left hemisphere of the brain (Zatorre et al. 1992; Belin et al. 2000). Therefore, the changes in cortical activation associated with unilateral deafness may be different for left versus right ear deafness (Bess et al. 1986).

For this analysis, the electrical potentials evoked by brief click trains were subjected to dipole modeling techniques to estimate the underlying current generators of these potentials (Mosher et al. 1992; Ponton et al. 1993, 2002; Scherg 1992). A mathematical model that describes the head as a 4-shell spherical volume conductor (Cuffin and Cohen 1979) and current sources as dipoles (Scherg and Von Cramon 1985; Snyder 1991) was used. The responses in the time window encompassing the $\mathrm{N}_{1 \mathrm{~b}} / \mathrm{P}_{2}$ and $\mathrm{Ta} / \mathrm{Tb}$ components (Näätänen and Picton 1987) were modeled using a pair of dipole sources, one oriented vertically and the other oriented laterally, in each hemisphere (Scherg and Von Cramon 1985). The parameters of the best-fit dipoles were then determined through spatiotemporal source modeling (STSM) techniques by using an iterative least-squares algorithm that fits the dipole-modeled potentials to the measured scalp potentials (Scherg and Von Cramon 1985, 1986; Snyder 1991). The source activity waveforms of the vertically and laterally oriented dipole sources were then used to measure the latencies and strengths of the ipsilateral and contralateral $\mathrm{N}_{1 \mathrm{~b}}$ / $\mathrm{P}_{2}$ and $\mathrm{Ta} / \mathrm{Tb}$ components, respectively. Interhemispheric differences (IHDs) in these parameters were then compared for left and for right ear unilateral deafness across the normal-hearing and unilaterally deaf subjects. The subject data included in this analysis were the same as those described in Ponton et al. (2001). 


\section{MATERIALS AND METHODS}

Subjects

Nineteen adults with profound unilateral deafness (7 males, 12 females; mean age 47 years; range 16-68 years; 9 with left-sided and 10 with right-sided deficit) and eight normal-hearing adults (ages 25-38; mean age 32 years; 4 males and 4 females) served as subjects. In all subjects, audiometric pure-tone thresholds were assessed prior to auditory evoked potential (AEP) recordings. The unilaterally deaf subjects were otherwise healthy and the audiograms in their intact stimulated ears were normal [hearing thresholds $\leq 25 \mathrm{~dB}$ hearing level (HL) for frequencies $\leq 4 \mathrm{kHz}]$. The pure-tone average (mean threshold of 0.5, 1.0, and $2.0 \mathrm{kHz}$ ) was $7 \mathrm{~dB} \mathrm{HL}$ and the mean speech discrimination score was $99 \%$ in the intact ears. All unilaterally deaf subjects had adult deafness; most had been deaf for between one and four years prior to being tested (duration of deafness was less than one year in only 1 subject and more than 4 years in 4 subjects). The average duration of hearing loss prior to recordings was 2.4 years (range $0.5-7.8$ years). All normal-hearing subjects had normal audiograms in both ears and no history of hearing deficit. Treatment of the subjects and execution of the studies was performed in accordance with the guidelines of the declaration of Helsinki.

\section{Evoked responses}

Testing took place in an electrically shielded, soundattenuated booth with the subjects seated in a comfortable reclining chair. Each stimulus presentation consisted of a brief train often 100 Ms clicks, with successive clicks within a train separated by $2 \mathrm{~ms}$. This 10-click train gave a unitary percept. Each subject was presented with 2000 such stimuli at an interstimulus interval of $510 \mathrm{~ms}$. The stimuli were delivered to the ear through earphones at $\approx 70 \mathrm{~dB}$ nHL.

Each subject had 31 electrode positions marked on the head by an experienced technician in accordance with the international 10-20 system. These 31 positions are shown in Figure 1. The AEPs were recorded with reference to the $\mathrm{F}_{\mathrm{pz}}$ electrode using a Neuroscan acquisition system. The ground electrode was placed approximately $2 \mathrm{~cm}$ to the right and $2 \mathrm{~cm}$ up from $\mathrm{F}_{\mathrm{pz}}$. Ocular movements were monitored on two different recording channels. Vertical eye movements were recorded by a pair of electrodes placed above and below the right eye. Horizontal eye movements were recorded by electrodes located on the outer canthus of each eye. A signal derived from the output of the module controlling stimulus presentation served as a trigger for sampling the EEG. The EEG data were recorded with a SynAmps 32-channel am-

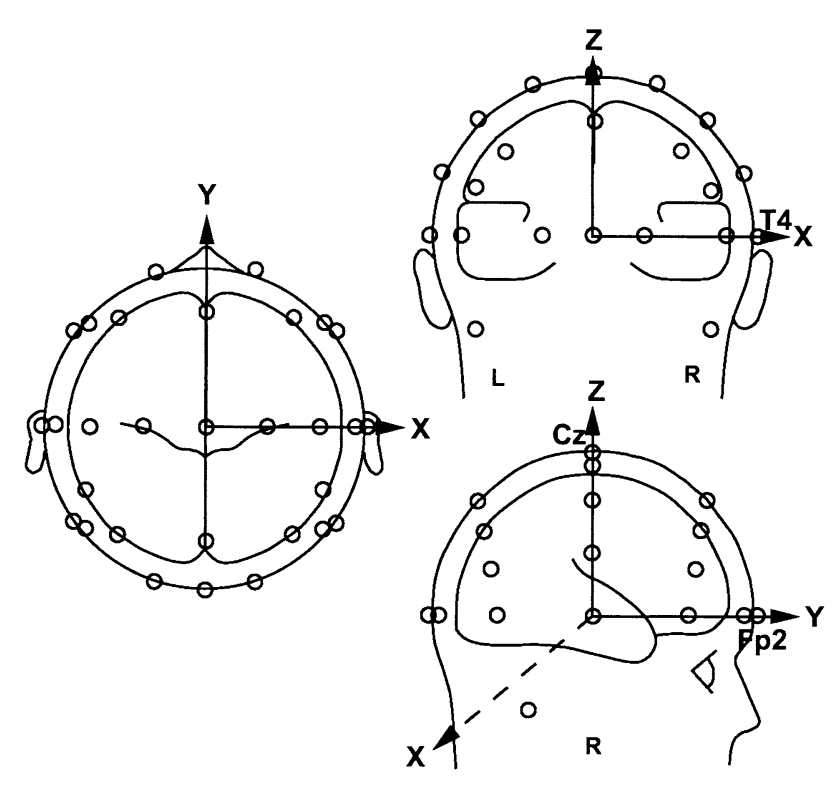

FIG. 1. Standard 10-20 locations of the 31-electrode configuration projected onto a sphere and the coordinate system used to describe these locations are depicted on the head views. The electrodes $F_{p z}$ $T_{3}, T_{4}$, and $\mathrm{O}_{z}$ form the equatorial plane and the vertex electrode $\mathrm{C}_{z}$ represents the north pole. In this system, the $z$ axis passes through the vertex $\left(C_{z}\right)$, the $x$ axis points to the right (through $T_{4}$ ), and the $y$ axis points forward (through $\mathrm{F}_{\mathrm{pz}}$ ).

plifier. The amplifier was set in DC mode and sampled the EEG at a rate of $1 \mathrm{kHz}$ with bandpass filter settings from DC to $200 \mathrm{~Hz}$. The data were recorded as single EEG epochs over an analysis window of 500 $\mathrm{ms}$, which included $100 \mathrm{~ms}$ prior to stimulus onset. AEPs were recorded to monaural stimulation of each ear in each normal-hearing subject and to stimulation of the intact ear in each unilaterally deaf subject.

Offline, the single EEG epochs were baseline corrected and subjected to an automatic artifact rejection algorithm, wherein sweeps containing activity in any channel that exceeded $\pm 150 \mathrm{MV}$ were excluded from subsequent analysis. A regression-based correction for ocular contamination was applied to the accepted data for vertical and horizontal eye movements. The remaining accepted sweeps (at least 1500) were corrected for eye movement contamination using the Neuroscan analysis software and then averaged. The activity from all channels was then averaged together to generate an average reference channel; this activity was then subtracted from each of the individual recording channels. This average referenced data were then bandpass filtered from 1 to $70 \mathrm{~Hz}$.

\section{Dipole source analyses — spatiotemporal source modeling}

Averaged response data were imported into the Brain Electric Source Analysis software (BESA, MEGIS 
Software, Munich, Germany). During importation the data were spline interpolated and resampled reducing the initial 500 points to 128 points per channel and then bandpass filtered from 1 to $50 \mathrm{~Hz}(6 \mathrm{~dB}$ / octave roll-off). The resulting data were then subjected to dipole source analyses. For detailed descriptions of source analysis, refer to Cuffin and Cohen (1979), Scherg and Von Cramon (1985, 1986), and Snyder (1991).

A 4 sphere head model, with an outer radius of 9 $\mathrm{cm}$ and with standard thickness and conductivity values for the various tissue types adapted from Cuffin and Cohen (1979), was selected as the volume conductor model for all subjects. The standard 10-20 positions of the 31 electrodes (projected onto a sphere) and the spherical coordinate system used in BESA are shown in Figure 1.

The fitting of the evoked potential data from multiple scalp electrodes can be performed either for a single timepoint or over a time window encompassing multiple data points. The latter modeling approach is termed as spatiotemporal source modeling (STSM) since it uses both spatial and temporal information in the fitting process. In general, STSM assumes fixed dipole locations and variable dipole orientations over the analysis time window (Scherg and Von Cramon 1985). The changes over time of the dipole strength at the source location are then represented by the dipole source waveforms (Scherg and Von Cramon 1985).

Regional current dipole sources (Scherg and Von Cramon 1985) were used as a first approximation to the cortical generators of the AEPs. A regional dipole source is a configuration of three mutually orthogonal dipoles with a common location. According to Scherg and Von Cramon (1985), the regional dipole model may be more appropriate for modeling neural activity generated in highly folded and functionally related cortical areas. Consistent with previous studies (Scherg and Von Cramon 1985; Ponton et al. 1993, 2002), we used a pair of regional dipoles as the initial source model, with one dipole in each hemisphere, since afferents from each ear (i.e., each cochlear nucleus) are known to project both contralaterally and ipsilaterally. Figure 2 shows the bilaterally symmetrical regional dipole model used in the present study, with each regional dipole consisting of three mutually orthogonal dipoles oriented along the $x, y$, and $z$ axes and sharing the same location. The odd numbers denote source components in the left hemisphere, while even numbers denote the components in the right hemisphere.

Dipole parameters were determined in BESA by a nonlinear, iterative, least-squares fitting procedure using the simplex algorithm for the spatial parameters (location) and a direct linear approach for the
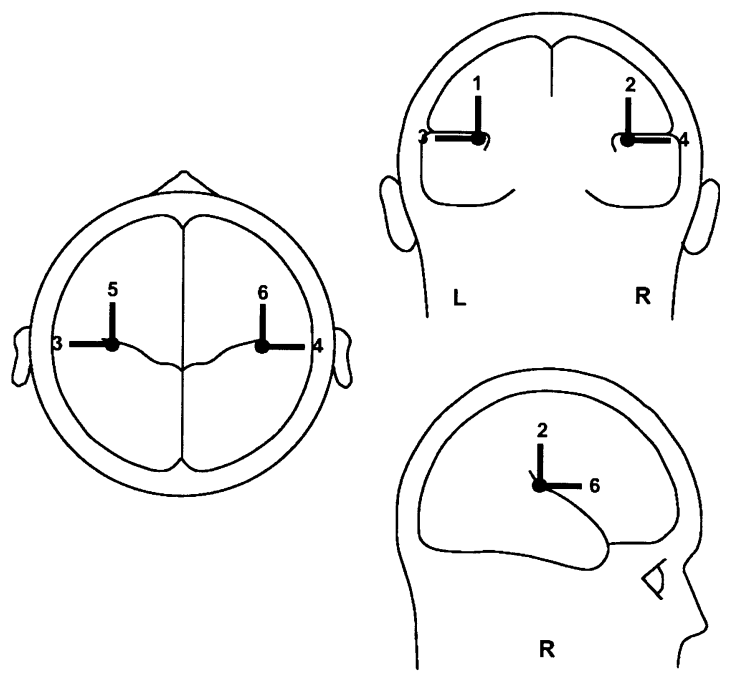

FIG. 2. Schematic representation of the bilaterally symmetrical regional dipole model used in the present study, with each regional dipole comprising three dipoles sharing the same location and oriented in mutually orthogonal directions. The odd numbers denote source components in the left hemisphere, while even numbers denote the components in the right hemisphere.

temporal parameters (magnitude). Dipole locations in the vicinity of the auditory cortex were provided as starting estimates to the fitting procedure in order to minimize the possibility of the algorithm getting trapped at a local minimum. The adequacy of the final fit was assessed by the residual variance (RV) criterion (Snyder 1991).

Details of the estimation procedure. The model analysis was restricted to the $70-210 \mathrm{~ms}$ period to specifically characterize neural events contributing to the auditory $\mathrm{N}_{1 \mathrm{~b}} / \mathrm{P}_{2^{-}}$and T-complex activities. Although the superior temporal gyrus is asymmetrical in humans, the constraint of hemispheric symmetry was imposed (with the two regional dipoles forming mirror images of each other with respect to the $y-z$ plane) to simplify the final source model solution. The symmetry constraint also reduces the number of parameters to be estimated in the nonlinear minimization step. In several subjects, the mastoid electrodes (M1, M2) were excluded because of excessive noise in the scalp waveforms at these sites. This reduces the residual variance of the fit, while dipole locations and source moments are almost unaffected because of the small number of sources and use of symmetry constraints. In a subsequent step, the symmetry constraint was released and the locations of the two regional sources were allowed to change independent of each other. With the exception of two subjects, the final locations of both regional sources were within $1 \mathrm{~cm}$ of their previous best-fit locations. Furthermore, no significant interhemispheric differences in locations of the regional sources were 
observed in any direction. Based on these findings, the hemispheric symmetry constraint was imposed on the regional source locations for all subsequent analysis. The source waveforms of the three dipoles of each regional source were then estimated by a direct linear approach.

We then attempted to orient the dipoles of each regional source such that most of the activity could be described by only two of the three dipoles that formed each regional source. Previous studies have indicated that the $\mathrm{N}_{1 \mathrm{~b}} / \mathrm{P}_{2}$ complex has a major contribution from a tangentially oriented source on the superior surface of the temporal lobe within the Sylvian fissure (Ponton et al. 1993, 2002; Scherg and Von Cramon 1985), while the T-complex is possibly due to a laterally oriented source on the lateral surface of the temporal lobe (Tonnquist-Uhlen et al., in press). As shown in Figure 2, the temporal lobe is angled downward in the head. To estimate the natural orientation of the tangential sources in the temporal lobes, the regional sources were rotated around the medial-lateral axis ( $x$ axis) until the amplitude of the $\mathrm{N}_{1 \mathrm{~b}} / \mathrm{P}_{2}$ peak-to-peak activity in dipoles 1 and 2 was maximized. Even though dipoles 1 and 2 may no longer be oriented vertically or have symmetrical orientations, they are still in the $y-z$ plane. For this reason, we shall continue to refer to them as vertical dipoles. In cases where the source location is close to the coronal midline, these dipoles are also approximately tangentially oriented. After rotating the vertical dipoles to their optimal orientation where $\mathrm{N}_{1 \mathrm{~b}} / \mathrm{P}_{2}$ activity was maximized, the orientations of the laterally oriented dipoles 3 and 4 were optimized independently in each hemisphere to further reduce the residual variance of the fit. With the exception of 3 subjects, the final orientations were within $10^{\circ}$ of the previous lateral orientation and the maximum difference between the orientations in the two hemispheres was only $14^{\circ}$. This step typically lowered the residual variance $(\mathrm{RV})$ of the fit by only about $1 \%-$ $2 \%$. Based on these results, we fixed the orientation of both dipoles 3 and 4 to be along the medial-lateral axis. In all subsequent analysis, source waveforms of the vertical dipoles were used to compute all parameters for the ipsilateral and contralateral $\mathrm{N}_{1 \mathrm{~b}} / \mathrm{P}_{2}$ complexes, while the source waveforms of dipoles 3 and 4 (oriented along the medial-lateral axis) were used to compute all parameters for the ipsilateral and contralateral T complexes.

Latency and amplitude parameters. Peaks were defined as the maximum positivity or negativity within a particular latency window of specific source waveforms. The waveforms of the vertically oriented dipoles ( 1 and 2 ) were used to identify the $\mathrm{N}_{1 \mathrm{~b}}(70-120$ $\mathrm{ms})$ and $\mathrm{P}_{2}(140-210 \mathrm{~ms})$ peaks, while the waveforms of the laterally oriented dipoles (3 and 4) were used to identify the Ta (70-130 ms) and Tb (110-180 ms) peaks. Peak-to-peak dipole moments (amplitudes) were also computed for the $\mathrm{N}_{1 \mathrm{~b}} / \mathrm{P}_{2}$ complex and the $\mathrm{Ta} / \mathrm{Tb}$ complex of the ipsilateral and contralateral sources. We used peak-to-peak amplitude measures, as opposed to peak-to-baseline measures, because it was sometimes difficult to clearly assess the individual peak-to-baseline amplitudes of all peaks in both hemispheres. Peak latency was defined as the time from the stimulus onset to the point used to calculate the amplitude measures (i.e., the most positive/negative point within the latency window). Furthermore, the RMS amplitude of the net dipole moment of each regional source over the $70-210 \mathrm{~ms}$ time window was also computed.

\section{Interhemispheric differences (IHD).}

The above amplitude and latency measures were then compared between the ipsilateral and contralateral hemispheres. Interhemispheric amplitude difference (IHAD) was expressed as a percentage of the summed values over hemispheres, i.e., IHAD $=100 *(\mathrm{CA}$ $-\mathrm{IA}) /(\mathrm{CA}+\mathrm{IA})$, where CA and IA denote the amplitude values in the hemisphere contralateral and ipsilateral, respectively, to the stimulated ear. An IHAD value of zero denotes full symmetry; positive values denote larger contralateral responses and negative values denote larger ipsilateral responses. Interhemispheric latency differences (IHLD) for each of the peaks $\left(\mathrm{N}_{1 b}, \mathrm{P}_{2}, \mathrm{Ta}, \mathrm{Tb}\right)$ were expressed as IHLD $=(I L-C L)$, where CL and IL denote the latency values of the corresponding peaks in the hemisphere contralateral and ipsilateral, respectively, to the stimulated ear.

\section{RESULTS}

In the following sections, ipsilateral and contralateral refer to the side that is the same as or opposite to, respectively, the stimulated ear. The latency and amplitude of a specific peak denote the latency and dipole strength, respectively, of that peak in the dipole source activity waveform. All interhemispheric differences in latencies and amplitudes then refer to the differences between the latencies and strengths of the ipsilateral and contralateral dipole sources.

\section{Dipole source locations and orientations}

Figure 3 shows the scalp waveforms for a normalhearing subject with monaural stimulation of the left ear. The $\mathrm{N}_{1 \mathrm{~b}} / \mathrm{P}_{2}$ complex is apparent in several channels. It is largest at $\mathrm{Cz}$, declines in amplitude away from the vertex, and is inverted at occipital 

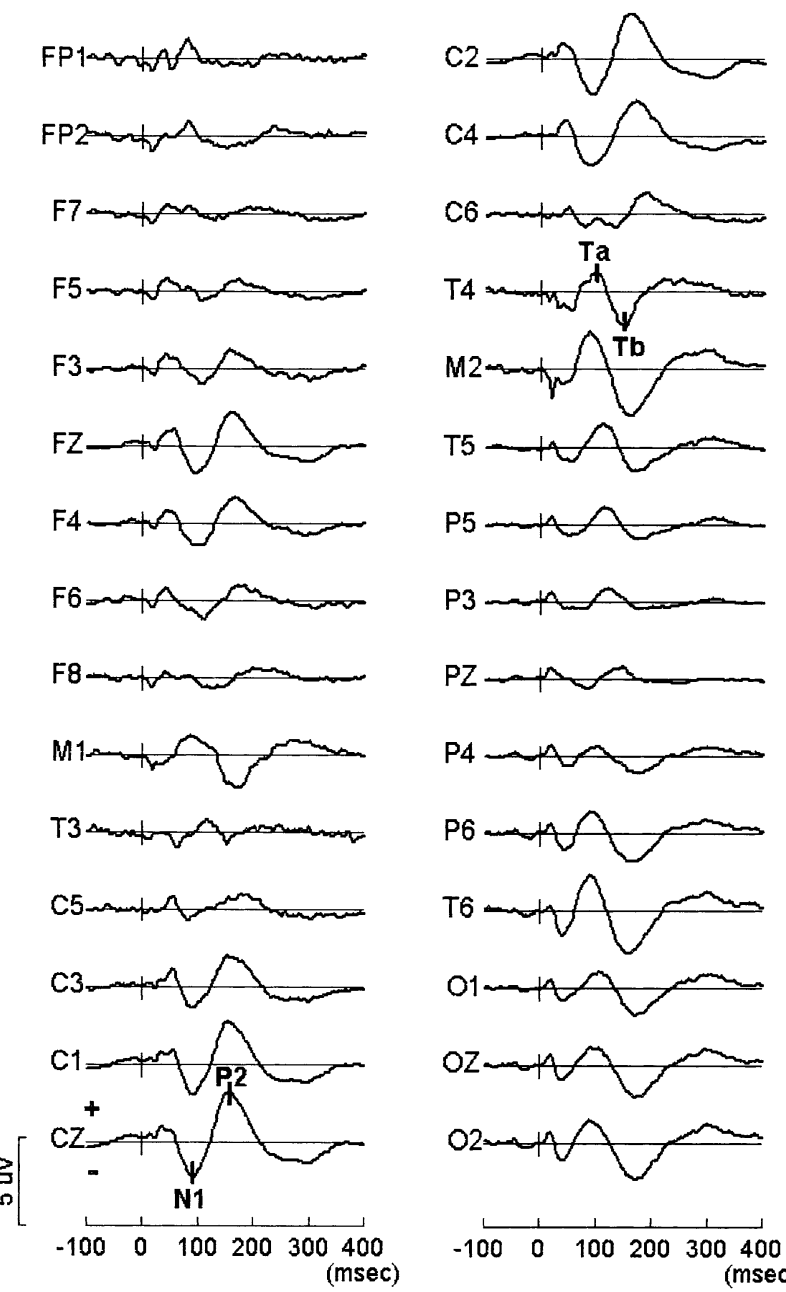

FIG. 3. Auditory evoked potentials from 30 scalp electrodes (average referenced) elicited by clicks presented monaurally to the left ear in one normal-hearing subject. The $\mathrm{N}_{1 b} / \mathrm{P}_{2}$ complex is apparent at the $C_{z}$ electrode, while the T-complex is apparent at the T4 electrode.

recording sites. The T-complex is apparent in the scalp waveforms at the temporal electrodes T3 and T4.

Figure 4 shows the locations of the best-fit dipoles superimposed on the corresponding head views for all normal-hearing (monaural left and monaural right stimulation) and unilateral deaf (monaural stimulation of the intact ear) subjects. Since a symmetrical regional dipole source model was used, the locations are shown at homologous positions in the two hemispheres. All source locations are clustered in the region of the superior temporal lobe of the head model. Table 1 gives the mean location coordinates of the regional source in the right hemisphere. Between-subject variability (standard deviation) was less than $8.6 \mathrm{~mm}$ along each coordinate axis. Significant differences in source locations were not found either between the normal-hearing and unilateral deaf groups or between the two stimulation sides in the

\section{- Normal Hearing - Unilaterally Deaf}
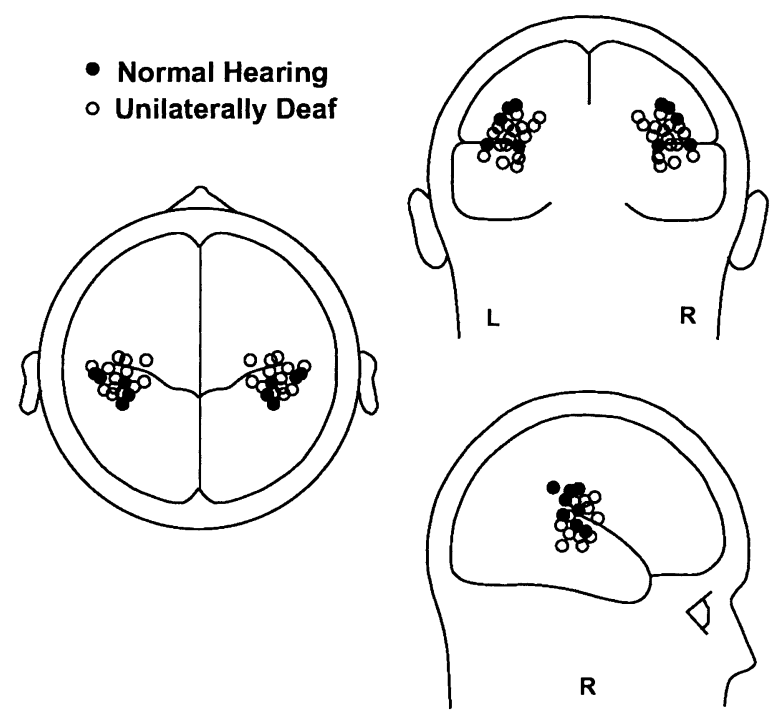

FIG. 4. Locations of the best-fit dipoles for all the normal-hearing (monaural left and right stimulation) and unilaterally deaf (monaural stimulation of the intact ear) subjects used in the present study superposed on the corresponding head views. No significant differences in locations were found between groups or between sides of stimulation.

medial-lateral $(x)$ and anterior-posterior $(y)$ directions. The only significant difference was found $(p=0.03)$ in the superior-inferior direction.

The regional sources were then rotated around the medial-lateral axis until the strength of the $\mathrm{N}_{1 \mathrm{~b}} / \mathrm{P}_{2}$ activity in dipoles 1 and 2 was maximized. The resulting orientation of these dipoles was at a mean angle of approximately $29^{\circ}$ and $25^{\circ}$ from the vertical in the head model in the normal-hearing and unilateral deaf population, respectively. Differences in the optimal orientations of dipoles 1 and 2 between normal-hearing and unilaterally deaf subjects were also not significant (not shown in Table 1). Figure 5a shows an example of this optimally tilted, final dipole configuration for a normal-hearing subject (monaural left ear stimulation). In this configuration, dipole sources 1 and 2 are oriented almost normal to the superior surface of the temporal lobe in the head; dipole sources 3 and 4 are still oriented laterally (along the direction of the $x$-axis) toward the temporal electrodes T3 and T4; while dipole sources 5 and 6 are in the $y-z$ plane, oriented at right angles (clockwise) to dipoles 1 and 2.

\section{Dipole source waveforms}

Figure $5 \mathrm{~b}$ depicts the estimated source waveforms of the dipoles shown in Figure 5a. Within both hemispheres, a distinct $\mathrm{N}_{1 \mathrm{~b}} / \mathrm{P}_{2}$ complex is apparent in the source waveforms of dipoles 1 and 2. The laterally oriented dipoles 3 and 4 show T-complex activity, 


\section{TABLE 1}

STSM regional dipole source location coordinates $(\mathrm{mm})$ in right hemisphere

\begin{tabular}{|c|c|c|c|c|}
\hline Subject type & & $x$ & $y$ & $z$ \\
\hline \multirow[t]{3}{*}{ Normal-hearing } & Left ear stimulation & $44.6 \pm 5.2$ & $-7.5 \pm 2.9$ & $22.399 \pm 7.1$ \\
\hline & Right ear stimulation & $43.5 \pm 4.6$ & $-9.8 \pm 5.6$ & $26.3 \pm 6.5$ \\
\hline & Average & $44.0 \pm 4.8$ & $-8.6 \pm 4.5$ & $24.3 \pm 6.9$ \\
\hline \multirow[t]{3}{*}{ Unilaterally deaf } & Left ear stimulation & $40.1 \pm 4.6$ & $-5.4 \pm 5.3$ & $16.8 \pm 7.1$ \\
\hline & Right ear stimulation & $40.2 \pm 8.2$ & $-6.0 \pm 6.2$ & $20.0 \pm 8.6$ \\
\hline & Average & $40.2 \pm 6.8$ & $-5.7 \pm 5.7$ & $18.7 \pm 7.9$ \\
\hline
\end{tabular}

which includes a positive peak at approximately 100 $\mathrm{ms}$ (Ta) and a negative peak at about $150 \mathrm{~ms}(\mathrm{~Tb})$. A second prominent peak at about $220 \mathrm{~ms}$ is also seen in source waveforms 3 and 4 . This is probably the P220 component generated by a radial source (Verkindt et al. 1994), which explains its presence in the source waveforms of dipoles 3 and 4 . We did not include this second peak in any data analyses. Source waveforms of dipoles 5 and 6 reflect small residual activity.

\section{Latency and amplitude parameters}

Group differences. Table 2A lists the mean latencies in the contralateral and ipsilateral hemispheres as well as the mean interhemispheric latency difference (IHLD) values of the different peaks in the normalhearing and unilaterally deaf subjects. In the normalhearing subjects, the peak latencies of $\mathrm{N}_{1 \mathrm{~b}}, \mathrm{P}_{2}$, Ta, and $\mathrm{Tb}$ are all earlier in the hemisphere contralateral to the stimulated ear with mean $( \pm \mathrm{SD})$ IHLD of 14.4 $( \pm 10.8)^{* *}, 7.7( \pm 6.4)^{*}, 8.3( \pm 9.2)^{* *}$, and $6.8( \pm 8.8)$ ms, respectively (** and $*$ denote $p<0.01$ and $p<0.05$ significance levels, respectively). In the unilaterally deaf subjects, the peak latencies of $\mathrm{N}_{1 \mathrm{~b}}, \mathrm{P}_{2}, \mathrm{Ta}$, and $\mathrm{Tb}$ are about the same in both hemispheres with mean $( \pm$ SD) IHLD of $1.9( \pm 11.2), 0.2( \pm 14.8), 0.9$ $( \pm 8.7)$, and $0.4( \pm 10.3) \mathrm{ms}$, respectively. The normalhearing and unilateral deaf groups differed significantly in IHLD values for $\mathrm{N}_{1 \mathrm{~b}}(p<0.01) * *$ and Ta $(p<$ $0.05)^{*}$, while IHLD values for $\mathrm{P}_{2}(p<0.06)$ and $\mathrm{Tb}(p$ $<0.06)$ were not significantly different.

Table 2B lists the root-mean-square (RMS) value of the dipole moment (units of nanoampere meter or $\mathrm{nA} \mathrm{m}$ ) computed in the 70-210 ms interval and the peak-to-peak dipole moment values of the $\mathrm{N}_{1 \mathrm{~b}} / \mathrm{P}_{2}$ and $\mathrm{Ta} / \mathrm{Tb}$ complexes. In the normal-hearing subjects, the RMS and peak-to-peak amplitudes of $\mathrm{N}_{1 \mathrm{~b}} / \mathrm{P}_{2}$ and $\mathrm{Ta} / \mathrm{Tb}$ are all larger in the hemisphere contralateral to the ear of stimulation, with mean $( \pm \mathrm{SD})$ interhemispheric amplitude differences (IHAD \%) of $24.5( \pm 10.8)^{* *}, 31.0( \pm 14.8)^{* *}, 20.6( \pm 23.0)$, respectively. In the unilaterally deaf subjects, the RMS and peak-to-peak amplitudes of $\mathrm{N}_{1 \mathrm{~b}} / \mathrm{P}_{2}$ and $\mathrm{Ta} / \mathrm{Tb}$ are also marginally larger in the hemisphere contralateral to the ear of stimulation, with mean $( \pm \mathrm{SD})$ IHAD $\%$ of $12.6( \pm 11.3) *, 17.0( \pm 23.1)$, and 7.1 $( \pm 24.0)$, respectively. All IHAD values of the normalhearing and unilateral deaf groups differed significantly in RMS $(p<0.01)^{* *}, \mathrm{~N}_{1 \mathrm{~b}} / \mathrm{P}_{2}(p 0.05)^{*}$, and Ta/ $\mathrm{Tb}(p<0.05)^{*}$.

The results of Table 2 have been summarized in Figure $6 \mathrm{a}$ and $\mathrm{b}$, which shows the mean IHLD and IHAD values for each group of subjects, respectively. It can be clearly seen that major peaks in the contralateral responses are earlier and larger than the corresponding peaks in the ipsilateral responses for the normal-hearing group. In contrast, the major peaks in the unilateral deaf group show similar latencies and reduced amplitude differences between hemispheres.

Ear differences. Table $3 \mathrm{~A}$ lists the IHLD values for the various peaks separated by the side of stimulation (monaural left vs. right stimulation). No significant differences are seen between IHLD values for the left and right stimulation within either group of subjects. It should be noted here that while data from each of the normal-hearing subjects was acquired under both monaural left and monaural right stimulation, the unilaterally deaf subjects were tested under monaural stimulation of only the intact ear (right ear in 10 subjects and left ear in 9 subjects). Thus, data for comparing IHLD values for left-sided and right-sided stimulation originates from different subjects in the unilateral deaf group.

Table 3B lists the IHAD values separated by the side of stimulation. No significant differences were found between IHAD values for monaural left and monaural right stimulation in the normal-hearing subjects. However, in the unilateral deaf group, the IHAD values for RMS moment $(p<0.05)^{*}, \mathrm{~N}_{1 \mathrm{~b}} / \mathrm{P}_{2}(p$ $<0.05)^{*}$, and $\mathrm{Ta} / \mathrm{Tb}(p<0.01) * *$ are all significantly different between monaural left and monaural right stimulation.

The results of Table 3 have also been summarized in Figure 7a and b; which show the mean IHLD and IHAD values for the normal-hearing and unilaterally deaf subjects separated by the side of stimulation. 


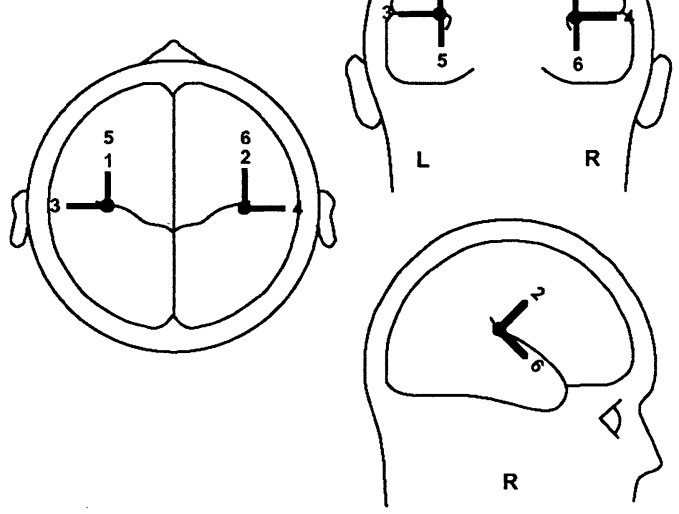

(b)

Ipsilateral
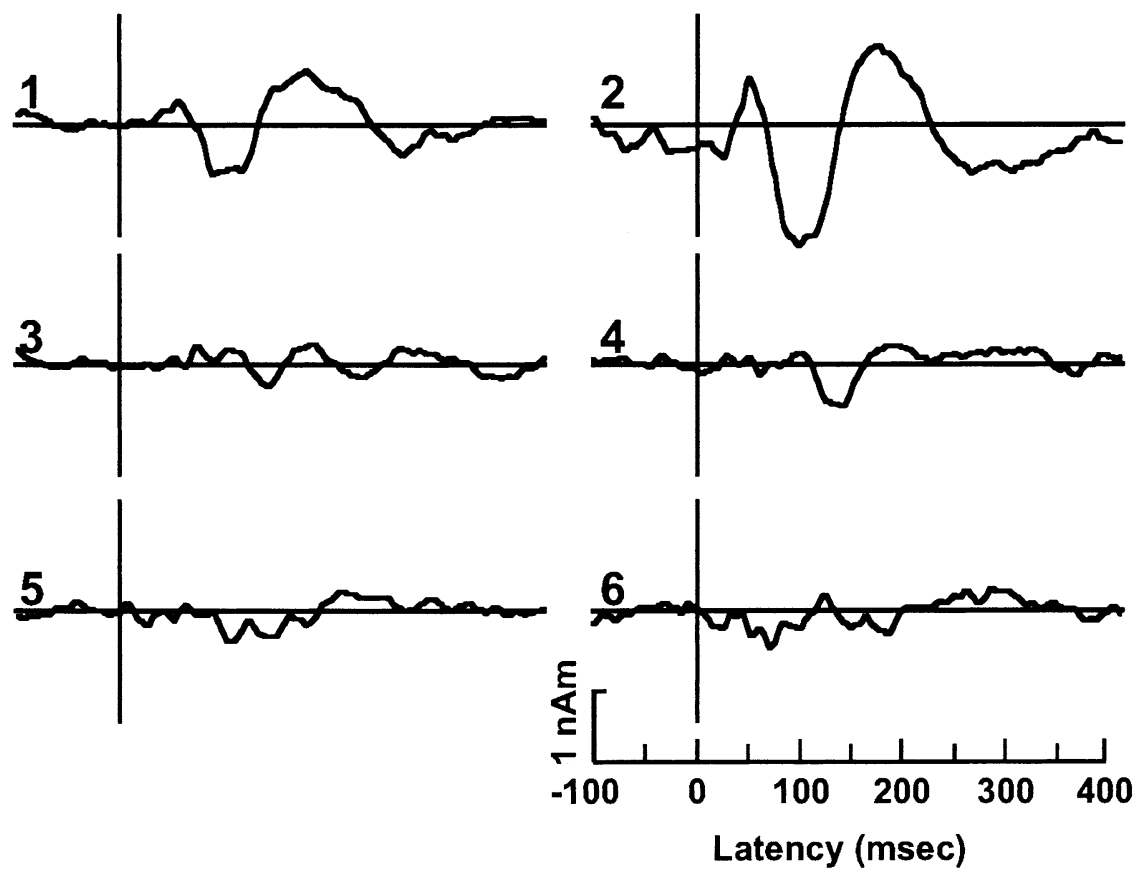

FIG. 5. a. The optimally tilted final dipole configuration for one normal-hearing subject (monaural left ear stimulation). In this configuration, dipoles 1 and 2 are approximately normal to the superior surface of the temporal lobe $\left(\mathrm{N}_{1 \mathrm{~b}} / \mathrm{P}_{2}\right)$, while dipoles 3 and 4 are laterally oriented (T-complex). b. Estimated source waveforms of the dipole sources in $\mathbf{a}$. Dipoles 1 and 2 reflect mostly the $\mathrm{N}_{1 \mathrm{~b}} / \mathrm{P}_{2}$ complex activity, while the laterally oriented dipoles 3 and 4 reflect mostly the T-complex activity. Dipoles 5 and 6 reflect small residual activity. The contralateral sources show shorter latencies and larger amplitudes than the ipsilateral sources.
While the two groups of subjects show nonsignificantly different IHLD values irrespective of the side of stimulation, the IHAD values of the unilaterally deaf subjects appear to depend on the ear of stimulation, with those stimulated in the right ear showing much reduced IHAD values (i.e., almost equal amplitudes in both hemispheres). Figures 8 and 9 show the individual source waveforms of the ipsilateral and contralateral vertical dipoles $\left(\mathrm{N}_{1 \mathrm{~b}} / \mathrm{P}_{2}\right)$ for all subjects. The numbers on the right side of each waveform indicate the IHAD values (\%). These figures also clearly show that unilaterally deaf subjects with monaural stimulation of the right ear have much reduced $\mathrm{N}_{1 \mathrm{~b}}$ / $\mathrm{P}_{2}$ IHADs compared with the normal-hearing subjects with monaural stimulation of either side or the unilaterally deaf subjects with monaural stimulation of the left ear. The results for the radial dipoles were very similar and are not shown here.

\section{DISCUSSION}

We investigated the effects of profound acquired unilateral deafness with dipole source modeling methods. The $\mathrm{N}_{1 \mathrm{~b}} / \mathrm{P}_{2}$ and $\mathrm{Ta} / \mathrm{Tb}$ components of the AEPs were modeled by a vertically and a laterally oriented dipole source in each hemisphere. The normal-hearing subjects showed significant ipsilateral- 


\section{TABLE 2A}

Mean latency parameters (ms) of different peaks of the hemispheres contralateral and ipsilateral to the side of stimulation (pooled for the side of stimulation) for the normal-hearing and unilaterally by deaf groups

\begin{tabular}{rlcrrr}
\hline Subject type & \multicolumn{1}{c}{ Hemisphere } & \multicolumn{1}{c}{$\mathrm{N}_{1 b}$} & $P_{2}$ & $T a$ & $T b$ \\
\hline Normal-hearing & Ipsilateral & $100.2 \pm 13.7$ & $167.6 \pm 9.9$ & $106.4 \pm 8.4$ & $143.1 \pm 16.7$ \\
& Contralateral & $85.8 \pm 9.5$ & $159.9 \pm 8.5$ & $98.1 \pm 7.1$ & $136.3 \pm 12.4$ \\
& IHLD & $14.4 \pm 10.8^{* *}$ & $7.7 \pm 6.4^{*}$ & $8.3 \pm 9.2^{* *}$ & $6.8 \pm 8.8$ \\
Unilaterally deaf & Ipsilateral & $91.8 \pm 11.3$ & $170.5 \pm 17.1$ & $100.9 \pm 12.2$ & $140.6 \pm 16.0$ \\
& Contralateral & $93.7 \pm 13.6$ & $170.3 \pm 17.6$ & $100.0 \pm 12.1$ & $140.2 \pm 12.6$ \\
& IHLD & $1.9 \pm 11.2$ & $0.2 \pm 14.8$ & $0.9 \pm 8.7$ & $0.4 \pm 10.3$ \\
\hline
\end{tabular}

TABLE 2B

Mean RMS and peak-to-peak dipole moment (nA m) or amplitude parameters in the source waveforms

\begin{tabular}{cllcr}
\hline Subject type & & \multicolumn{1}{c}{$R M S$} & $N_{1 b}-P_{2}$ & \multicolumn{1}{c}{$T a-T b$} \\
\hline Normal-hearing & Contralateral & $1.21 \pm 0.28$ & $2.8 \pm 0.69$ & $0.91 \pm 0.57$ \\
& Ipsilateral & $0.73 \pm 0.17$ & $1.47 \pm 0.44$ & $0.63 \pm 0.42$ \\
\multirow{4}{*}{ Unilaterally deaf } & IHAD (\%) & $24.5 \pm 10.8^{* * *}$ & $31.0 \pm 14.8^{* *}$ & $20.6 \pm \mathbf{2 3 . 0}$ \\
& Contralateral & $0.93 \pm 0.28$ & $2.13 \pm 0.78$ & $0.89 \pm 0.44$ \\
& Ipsilateral & $0.73 \pm 0.28$ & $1.64 \pm 0.9$ & $0.78 \pm 0.39$ \\
& IHAD (\%) & $12.6 \pm 11.3$ & $17.0 \pm 23.1$ & $7.1 \pm 24.0$ \\
\hline
\end{tabular}

${ }^{* *} p<0.01,{ }^{*} p<0.05$ (significance level for differences between contralateral and ipsilateral values).

${ }^{a}$ Interhemispheric latency differences are computed as IHLD $=$ (ipsilateral latency-contralateral latency).

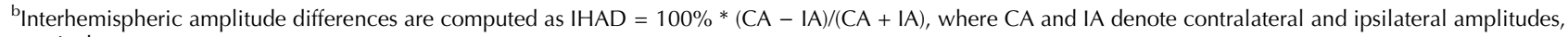
respectively.

contralateral latency and amplitude differences for the source waveforms, with contralateral source activities that were typically larger and peaked earlier than the ipsilateral activities regardless of the ear that was stimulated. For unilaterally deaf subjects, analysis of the source dipole activity demonstrated reduced interhemispheric amplitude differences that were ear dependent, whereas latencies were not different across hemispheres. The changes in amplitude were found only in those subjects affected by profound left ear unilateral deafness.

\section{Dipole source analysis approach}

The aim of this study was to determine if profound unilateral deafness has any effects on the central auditory system that can be detected using electrophysiological recordings of cortical responses to basic click train stimulation. Auditory evoked activity was modeled using bilaterally symmetrical regional dipoles. Peak latencies and amplitudes of late-latency AEP components were estimated from the corresponding source waveforms of the best-fit dipoles. Interhemispheric differences in these measures were computed for all normal-hearing and unilaterally deaf subjects and used to assess effects of unilateral deafness on central auditory system activity.

As noted by Näätänen and Picton (1987) and demonstrated by the intracranial recordings of a number of investigators (e.g., Liègeois-Chauvel et al.
1991, 1994, 1999; Steinschneider et al. 1999), the $\mathrm{N}_{1}$ potential as recorded from the scalp represents the sum of three or more generators. It is certainly the case that the regional dipole source model represents a first approximation and a center of gravity for this complex generator activity. However, the analyses applied to the data reported in this study represent a significant advance over studies that limit their analyses to a selected very small subset of all recording electrodes used in an experiment.

It may be argued that IHDs in latencies and amplitudes in our results can arise primarily from IHDs in locations/orientations of the dipole sources. This possibility has been addressed in our source model by independently optimizing the locations and orientations of the sources in the two hemispheres. Based on the results of these optimizations, hemispheric symmetry constraints were imposed on (1) locations of the regional sources and (2) orientations of the laterally oriented dipoles. The vertical dipoles were allowed to have different orientations in the hemispheres. In order to assess the effects of the two symmetry constraints used in the study, analyses were also done without imposing any constraints. The IHDs in latencies/amplitudes changed, on average, by $1.1 \%-1.9 \%$ from their previous values obtained with the constrained source model. This suggests that the constraints make the source model simpler without sacrificing accuracy of IHD measures. This was further supported by the fact that the IHDs in RMS 


\section{(a)}

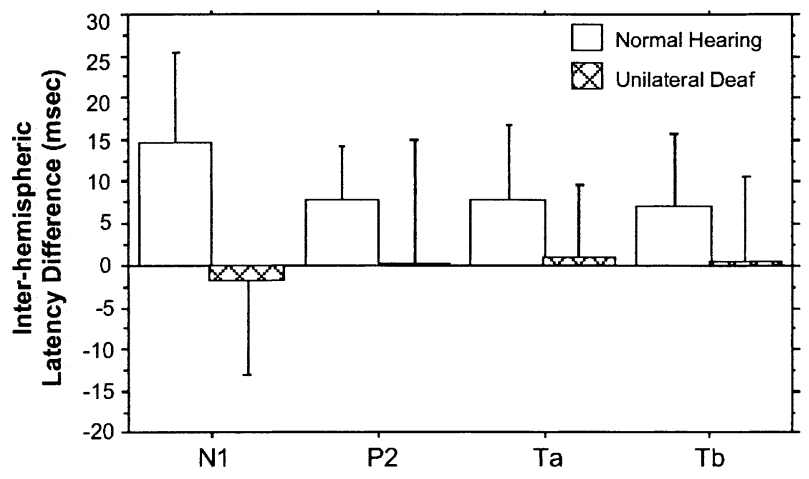

(b)

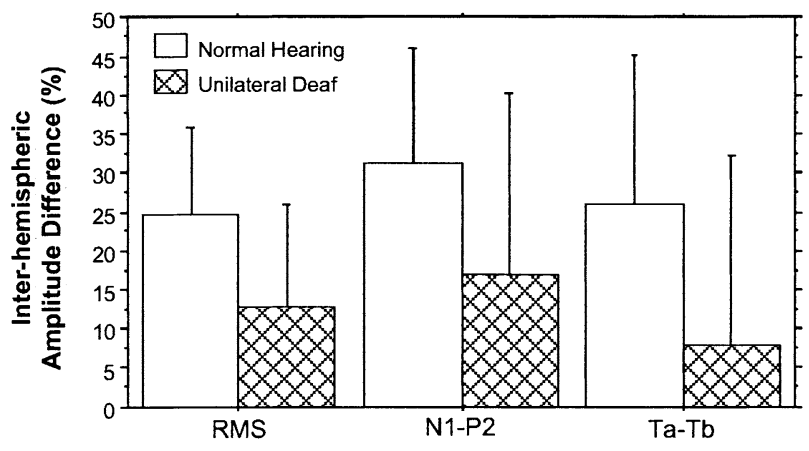

FIG. 6. a. Mean interhemispheric latency differences (IHLD) $=(\mathrm{IL}-\mathrm{CL})$ for the normal-hearing $(n=16)$ and unilaterally deaf subjects $(n=19)$, where IL and CL denote the latency of the peaks in the source waveforms of the ipsilateral and contralateral hemispheres, respectively. The contralateral latencies are all shorter in the normal-hearing group, while interhemispheric differences are close to zero in the unilateral deaf group. b. Mean interhemispheric amplitude differences $($ IHAD $)=100 \% *(C A-I A) /(C A+I A)$ for the two groups, where IA and CA denote the amplitudes (dipole moments) in the ipsilateral and contralateral hemispheres, respectively. The contralateral amplitudes are significantly larger than the ipsilateral amplitudes in the normal-hearing group; these differences are significantly reduced in the unilaterally deaf group.

amplitude measures, which take into account all the components of each regional source and are independent of the component orientations, are of the same order as IHDs in amplitudes of the individual peaks.

\section{Stimulus factors}

Unlike most studies of human auditory cortical activity, clicks trains were used as stimuli in this investigation. In our previous studies of cochlear implant patients (e.g., Ponton et al. 1993, 1996a,b, 1999, 2000), auditory stimulation was produced by applying current pulse trains to the implant hardware. To parallel this as closely as possible, acoustic click trains were used as stimuli for our normal-hearing and unilaterally deaf subjects. The spectral content of the click is very broad; for a 100 Ms click, the first energy null occurs at $10 \mathrm{kHz}$. This raises the question of whether a different result might have been obtained if more frequency-specific (i.e., high versus low tones) tonal stimuli had been used to generate the evoked potentials. Evoked potential and current source density data recorded in monkeys by Reser et al. (2000) indicate a differential representation of highand low-frequency units in the binaural interaction columns of area AI of primary auditory cortex. Lowfrequency areas in AI are dominated by EE (excitatory contralateral/excitatory ipsilateral) units, whereas high-frequency areas are dominated by EI units (excitatory contralateral/inhibitory ipsilateral). If human auditory cortex has a similar organization, then differential effects might be observed with tonal stimulation of low versus high frequencies. However, as noted by Jacobson et al. (1992), low-frequency tonal stimulation $(250 \mathrm{~Hz})$ produces significantly larger $\mathrm{N}_{1}$ amplitude than higher-frequency stimulation ( 1 or $4 \mathrm{kHz}$ ). Thus, click-evoked $\mathrm{N}_{1}$ activity is more likely dominated by the low- than the high-frequency content of the click. This leads to the prediction that the results reported in the present study might reflect mostly the activity of the low-frequency EE cortical units in AI.

\section{Cortical reorganization due to hearing loss}

Using source waveforms to assess IHDs, we found that differences between the ipsilateral and contralateral responses in unilaterally deaf subjects were significantly altered from the normal-hearing subjects. In normal-hearing individuals, the latencies and amplitudes of the major peaks observed in the dipole source activity of the contralateral hemisphere were earlier and larger than those on the ipsilateral side. However, these latency and amplitude differences between the responses on the two sides were significantly smaller in unilaterally deaf subjects. This confirms previous findings based on regional averages of AEPs measured at central electrode sites (Ponton et al. 2001).

Vasama and Mäkelä (1997) reported similar findings in unilaterally deaf subjects. In half of their subjects, they observed shorter response latencies and larger dipole moments in the auditory evoked magnetic fields over the hemisphere ipsilateral to the stimulation. Similar alterations in interhemispheric amplitude differences due to profound unilateral deafness have also been reported by estimating the level of cortical activity in response to tonal stimulation (Scheffler et al. 1998) using fMRI. This study reported a strong lateralization of the cortical response toward the contralateral hemisphere in normal-hearing subjects, while a very weak lateralization 


\section{TABLE 3A}

Mean interhemispheric latency differences (IHLD) for the normal-hearing and unilaterally deaf groups separated by the side of monaural stimulation

\begin{tabular}{|c|c|c|c|c|c|}
\hline \multirow[t]{2}{*}{ Subject type } & \multirow[t]{2}{*}{ Stimulated ear } & \multicolumn{4}{|c|}{$I H L D(m s)$} \\
\hline & & $N_{1 b}$ & $P_{2}$ & $T a$ & $T b$ \\
\hline \multirow[t]{2}{*}{ Normal-hearing } & Left & $15.6 \pm 13.7$ & $10.4 \pm 6.6$ & $9.1 \pm 9.6$ & $5.1 \pm 6.1$ \\
\hline & Right & $13.3 \pm 7.7$ & $5.1 \pm 5.4$ & $6.1 \pm 9.2$ & $8.5 \pm 11.1$ \\
\hline \multirow{2}{*}{ Unilaterally deaf } & Left & $2.3 \pm 12.0$ & $2.0 \pm 15.2$ & $1.0 \pm 11.9$ & $-1.1 \pm 12.1$ \\
\hline & Right & $-5.5 \pm 9.7$ & $-1.4 \pm 14.8$ & $0.7 \pm 4.4$ & $1.9 \pm 8.6$ \\
\hline
\end{tabular}

TABLE 3B

Mean interhemispheric amplitude differences (IHAD) for normal-hearing and unilateral deaf groups seperated by the side of monaural stimulation

\begin{tabular}{lcccc}
\hline Subject type & Stimulated ear & \multicolumn{3}{c}{$I H A D(\%)$} \\
\hline & & $R M S$ & $N_{1 b}-P_{2}$ & $T a-T b$ \\
\cline { 3 - 5 } Normal-hearing & & & \\
& Left & $22.0 \pm 11.1$ & $30.4+17.5$ & $29.6 \pm 19.8$ \\
Unilaterally deaf & Right & $27.0 \pm 11.7$ & $31.8 \pm 12.8$ & $20.9 \pm 19.1$ \\
& Left & $19.5 \pm 12.8$ & $29.5 \pm 25.1$ & $25.2 \pm 18.7$ \\
& Right & $7.1 \pm 11.6^{*}$ & $5.9 \pm 15.0^{*}$ & $-7.9 \pm 17.9^{* *}$ \\
\hline
\end{tabular}

${ }^{* *} p<0.01, * p<0.05$ (significance level for difference between values for left-sided and right-sided monaural stimulation).

toward the hemisphere contralateral to the intact ear was found in unilaterally deaf subjects. While fMRI has good spatial resolution that translates to accurate estimation of cortical activity levels, its poor temporal resolution (of the order of 2-5 s) does not allow a comparison of response latencies in the two hemispheres. In contrast, the excellent temporal resolution of electrophysiological recordings (of the order of $1 \mathrm{~ms}$ ) allowed us to assess any alterations in interhemispheric latency differences in the present study. This millisecond level temporal resolution revealed significant alterations in IHLDs due to unilateral hearing loss. That is, while normal-hearing subjects had shorter latencies in the contralateral hemisphere, the latencies of the responses in the contralateral and ipsilateral hemispheres were almost equal in the unilaterally deaf subjects.

The mechanisms responsible for changes demonstrated in our data are likely related to those that characterize the normal hemispheric asymmetry. The shorter latencies for contralateral stimulation can be understood because the contralateral pathway in mammals contains a greater number of nerve fibers and represents a more direct route with fewer synapses to cortex than the ipsilateral pathway (Adams 1979; Brunso-Bechtold et al. 1981; Coleman and Clerici 1987). Central auditory system activity evoked by monaural presentation generally is stronger and has lower activation thresholds in the contralateral than in the ipsilateral auditory pathway (Popelar et al. 1994; Reale et al. 1987; Kitzes 1984). Stronger onset synchrony between the firings of single units in cat auditory cortex correlates with shorter latency (Brosch and Schreiner 1999). Thus, larger evoked potential amplitudes on the side contralateral to the stimulated ear may result from both the larger number of activated neurons and a stronger onset synchrony between the firings. According to our data, the amount of amplitude asymmetry in the normalhearing subjects is the same for left ear and right ear stimulation. While these observed differences between the two hemispheres reached significance only for the tangential dipoles, the trend for the radial dipoles was the same.

We found no significant difference in the latencies of the $\mathrm{N}_{1 \mathrm{~b}} / \mathrm{P}_{2}$ and $\mathrm{Ta} / \mathrm{Tb}$ components for contralateral stimulation in unilateral deaf and normal-hearing subjects. Furthermore, in unilaterally deaf subjects, the ipsilateral and contralateral responses became nearly identical in the magnitude of activation as well as in the time of activation for the $\mathrm{N}_{1 \mathrm{~b}} / \mathrm{P}_{2}$ and $\mathrm{Ta} / \mathrm{Tb}$ components. In the visual system, behavioral measures (Bjorklund and Lian 1993) and evoked potential measures (Nalcaci et al. 1999) produce a similar estimate of $12 \mathrm{~ms}$ for interhemispheric transfer. For the auditory system, Bjorklund and Lian (1993) estimate the interhemispheric transfer at approximately $16 \mathrm{~ms}$. Combined, these data predict that the primary locus of symmetric bilateral activation occurs at a more peripheral level in the auditory system where conduction velocities are high and latency differences are minimal (Kitzes 1984), rather than by an unmasking of hemispheric callosal transfer. It is important to note that initial auditory cortical acti- 
(a)

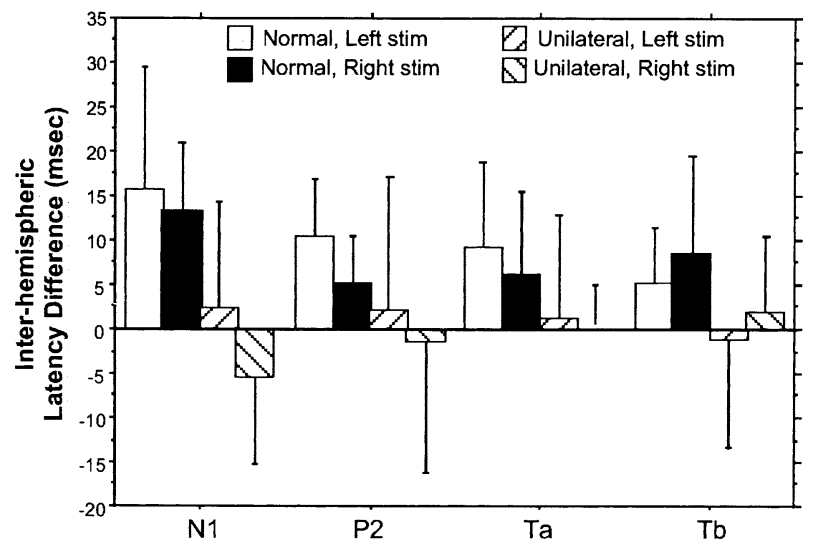

(b)

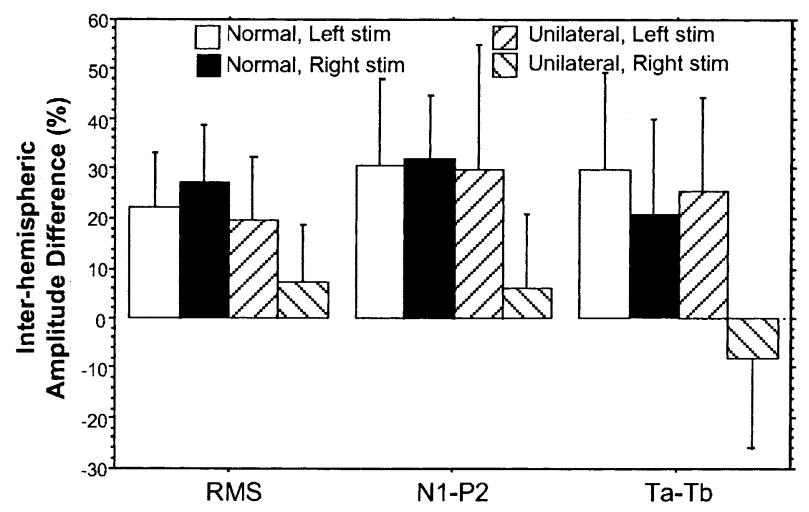

FIG. 7. Mean IHLD values for the normal-hearing and unilaterally deaf subjects separated by ear of stimulation. The two groups of subjects show similar IHLD values irrespective of the side of stimulation, b. Mean IHAD values for the normal-hearing and unilaterally deaf subjects separated by ear of stimulation. IHAD values of the unilaterally deaf subjects appear to depend on the ear of stimulation, with those stimulated in the right ear showing much reduced IHAD values (i.e., almost equal amplitudes in both hemispheres).

vation may occur as early as $19 \mathrm{~ms}$. Therefore, considerable processing has undoubtedly occurred by $100 \mathrm{~ms}$. Thus, in order to evaluate the locus of change produced by unilateral deafness, it will be necessary to examine the latency and amplitude properties of the middle-latency auditory evoked potentials which occur 19-60 ms after stimulus onset.

\section{Reorganization and side of hearing loss}

We further analyzed the IHDs to assess if there were any dependence on the side of stimulation/hearing loss in either subject group. The rationale was based on previous studies that have reported that sound recognition in noise and sound localization are two functions, which may be dependent on the side of the hearing loss. For example, Hartvig et al. (1989) found
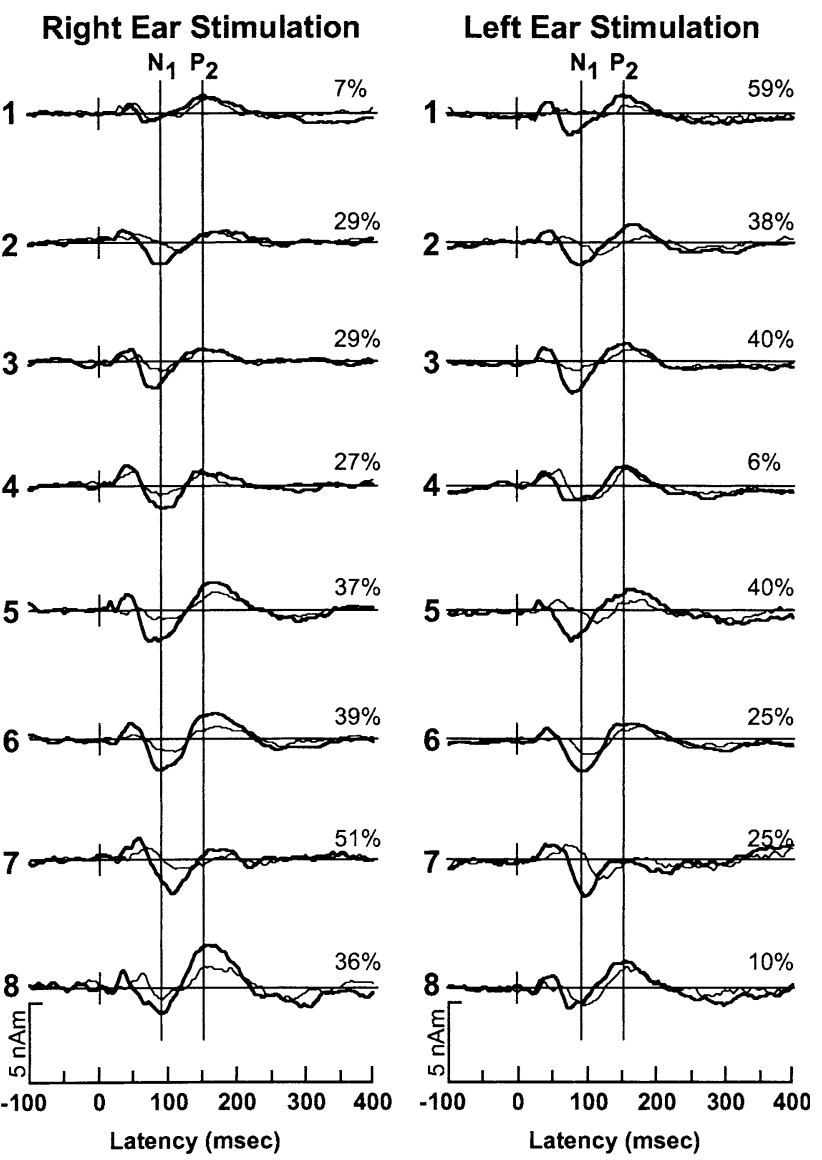

FIG. 8. Source waveforms of the ipsilateral (thin lines) and contralateral (thick lines) vertical dipoles $\left(\mathrm{N}_{1 b} / \mathrm{P}_{2}\right)$ in the normal-hearing subjects for monaural stimulation of the left and right ear. The numbers $1-8$ on the left side of each pair of waveforms indicate the subjects, while the numbers on the right side of each waveform indicate the corresponding IHAD values (\%).

that children who are unilaterally deaf in the right ear perform significantly poorer in verbal subtests that are sensitive to minor input/processing damages than those impaired in the left ear. Gustafson et al. (1995) showed that individuals with experimentally induced unilateral conductive hearing loss in the right ear are affected significantly more in their localization ability than those with hearing loss in the left ear. In the present study, we found evidence that the side of hearing loss has differential effects on the modification of the central auditory system. We found that the effect of left ear unilateral deafness (right ear stimulation) was to evoke equal cortical activation in the right and left hemispheres for clicks, whereas right ear unilateral deafness (left ear stimulation) produced normal asymmetry, i.e., contralateral right hemisphere larger than ipsilateral left hemisphere activation. This suggests that compensatory plasticity does not take place for a right ear hearing loss. It is important to note that there is a left hemispheric specialization in humans (Johnsrude 


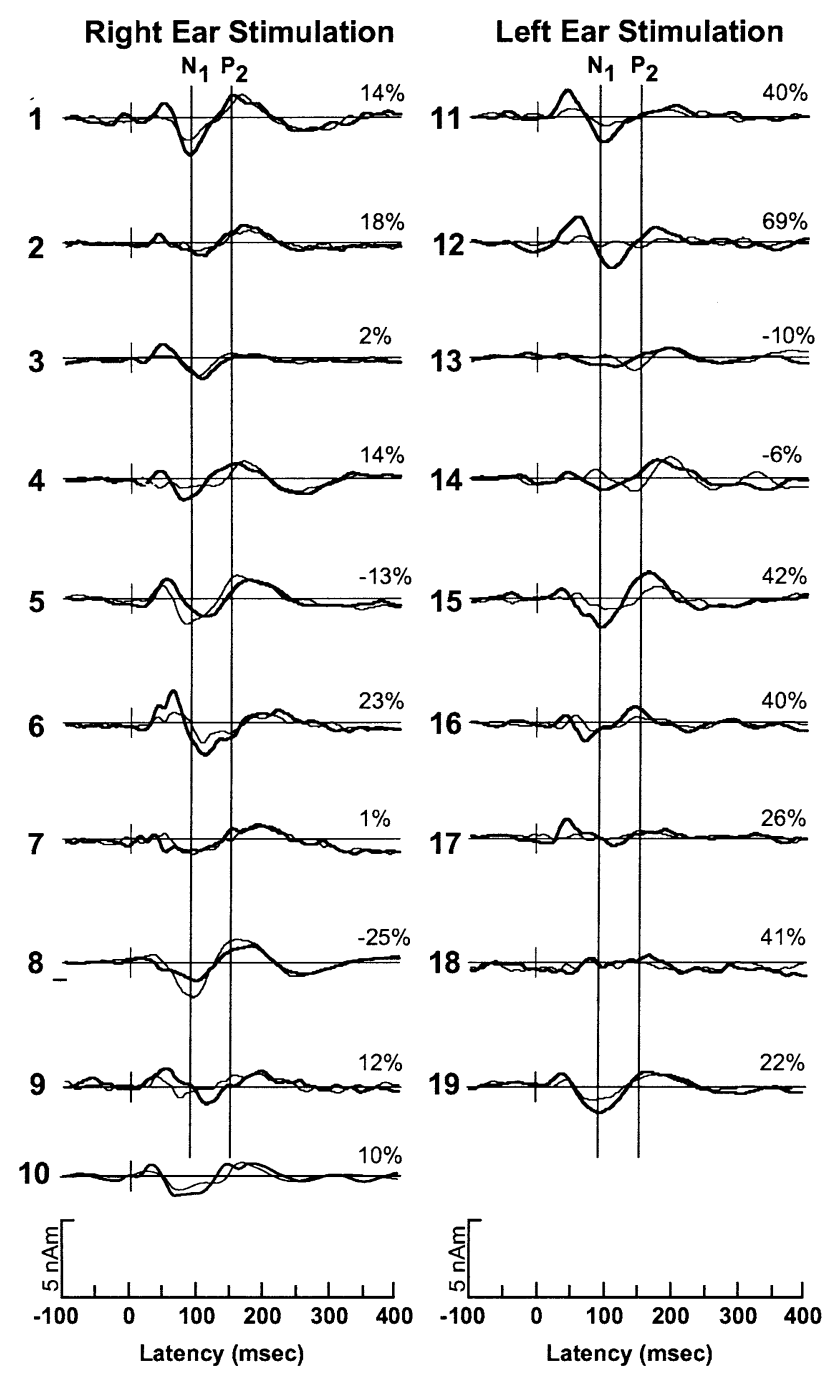

FIG. 9. Source waveforms of the ipsilateral (thin lines) and contralateral (thick lines) vertical dipoles $\left(\mathrm{N}_{1 \mathrm{~b}} / \mathrm{P}_{2}\right)$ in the unilaterally deaf subjects for monaural stimulation ofthe left and right ear. The numbers on the left side of each pair of waveforms indicate the subjects, while the numbers on the right side of each waveform indicate the corresponding IHAD values (\%).

et al. 1997) and guinea pigs (King et al. 1999) for processing of acoustic transients such as clicks. Thus, in the unilaterally deaf, stimulating the left ear with clicks maintained the normal hemispheric asymmetry and there was no compensatory transfer to the normally-transient-dominant left hemisphere. In contrast, activating the dominant left hemisphere by right ear stimulation in the unilaterally deaf did result in equal activation of both hemispheres. On the basis of the nearly equal latencies for left and right ear stimulation in the unilaterally deaf, it appears highly unlikely that there is compensatory transfer at the callosal level from the left to the right hemisphere. If such compensation occurred by way of the corpus callosum, interhemispheric latency differences (contra $<$ ipsi) should remain. However, the alternative is that changes in inhibition taking place at the brainstem level or midbrain level (Mossop et al. 2000) result in this symmetric activation of auditory cortex. This would require a profound difference in effect regarding the side of hearing loss in the initiation of these changes. This asymmetry could be in the afferent pathway leading to the midbrain but could potentially also result from an asymmetric gain control mediated by the corticofugal pathways at the midbrain level (Suga et al. 2000).

Stimulating with pulsed tones presented at $6 / \mathrm{s}$ (Scheffler et al. 1998) also resulted in increased symmetry in the unilaterally deaf as measured using fMRI. These data, although based on only five subjects, suggest that left unilaterally deaf subjects $(n=2)$ with an intact right ear showed more interhemispheric symmetry than the right unilaterally deaf $(n=3)$. These results are thus similar to ours, suggesting that the type of stimulation and the dominance of the left hemisphere in processing transient sounds is an aspect that is independent of the degree of symmetrization of interhemispheric activity. This argues once more for changes peripheral to auditory cortex.

\section{CONCLUSIONS}

The present study provides evidence of central auditory system reorganization due to profound left ear unilateral deafness in adult humans. In contrast, it appears that unilateral right ear deafness does not result in plastic changes and leaves the left hemisphere with much less activation than the right. It is possible that the use of a regional dipole source model somehow masks subtle compensatory processes that might follow right ear deafness. Further studies are clearly needed that combine both behavioral measures of auditory and speech function with evoked potential recordings using a higher number of electrodes to allow more refined source modeling. Nevertheless, the present results provide no evidence of compensatory plasticity following right ear deafness, i.e., there is no compensatory increase in activation of the ipsilateral left hemisphere. This may underlie the demonstrated poorer verbal performance of unilaterally right ear deaf compared to unilaterally left ear deaf (Hartvig et al. 1989).

For those individuals with profound bilateral deafness considering a cochlear implant, these findings may have implications for determining which side is implanted. Preliminary analyses suggest that the pattern of results observed in the unilateral deaf is the same in cochlear implant users (Ponton et al., unpublished). All other known factors being equal (e.g., degree of hearing loss, etc.), it would seem most prudent to place the implant on the right side, thus 
stimulating the pathway that produces the most robust activation of the typically speech-dominant left hemisphere. At the very least, as the number of individuals who are binaurally implanted increases, a careful examination of speech processing capabilities as a function of side of stimulation is clearly warranted.

\section{REFERENCES}

Adams JC. Ascending projections to the inferior colliculus. J. Comp. Neurol. 183:519-538, 1979.

Belin P, Zatorre RJ, Lafaille P, Ahad P, Pike B. Voice-selective areas in human auditory cortex. Nature. 403:309-312, 2000.

Bess F, Klee T, Culbertson J. Identification, assessment, and management of children with unilateral sensorineural hearing loss. Ear Hear. 7:43-51, 1986.

BJORKLund RA, LiAn A. Interhemispheric transmission time in an auditory two-choice reaction task. Scand. J. Psychol. 34:174-182, 1993.

Brosch M, Schreiner CE. Correlations between neural discharges are related to receptive field properties in cat primary auditory cortex. Eur. J. Neurosci. 11:3517-3530, 1999.

Brunso-Bechtold JK, Thompson GC, Masterson RB. HRP study of the organization of auditory afferents ascending to the central nucleus of the inferior colliculus in cat. J. Comp. Neurol. 197:705-722, 1981.

Coleman JR, Clerici WJ. Sources of projections to subdivisions of the inferior colliculus in the rat. J. Comp. Neurol. 262:215-226, 1987.

Cuffin BN, Cohen D. Comparison of the magnetoencephalogram and electroencephalogram. Electroencephalogr. Clin. Neurophysiol. 47:132-146, 1979.

EgGermont JJ, Komiya H. Moderate noise trauma in juvenile cats results in profound cortical topographic map changes in adulthood. Hear. Res. 142:89-101, 2000.

Fujuki N, Naito Y, Nagamine T, Shiom Y, Hirano S, Honjo I, ShiBASAKI H. Influence of unilateral deafness on evoked magnetic field. Neuro report. 3129-3133, 1998.

Gustafson TJ, Hamill TA. Differences in localization ability in cases of right versus left unilateral simulated conductive hearing loss. J. Am. Acad. Audiol. 6:124-128, 1995.

Hartvig JJ, Jensen J, Borre S, Johansen PA. Unilateral sensorineural hearing loss in children and auditory performance with respect to right/left ear differences. Br. J. Audiol. 23:207-213, 1989.

Harrison RV, Nagasawa A, Smith DW, Stanton S, Mount RJ. Reorganization of auditory cortex after neonatal high frequency cochlear hearing loss. Hear. Res. 54:11-19, 1991.

Jacobson GP, Lombardi DM, Gibbens ND, Ahmad BK, Newman CW. The effects of stimulus frequency and recording site on the amplitude and latency of multichannel cortical auditory evoked potential (CAEP) component N1. Ear Hear. 13:300-306, 1992.

Johnsrude S, Zatorre RJ, Milner BA, Evans AC. (1997) Left-hemisphere specialization for the processing of acoustic transients. Neuro report 8:1761-1765, 1992.

King C, Nicol T, McGee T, Kraus N. Thalamic asymmetry is related to acoustic signal complexity. Neurosci. Lett. 267:89-92, 1999.

KITZES LM. Some physiological consequences of cochlear destruction in the inferior colliculus of the gerbil. Brain Res. 306:171178, 1984.
Liègeois-Chauvel C, Musolino A, Chauvel P. Localization of the primary auditory area in man. Brain. 114:139-153, 1991.

Liègeois-Chauvell C, Musolino A, Badier JM, Marquis P, Chauvel P. Evoked potentials recorded from the auditory cortex in man: evaluation and topography of the middle latency components. Electroencephalogr. Clin. Neurophysiol. 92:204-214, 1994.

Liègeois-Chauvel C, de Graaf JB, Laguitton V, Chauvel P. Specilaization of left auditory cortex for speech perception in man depends on temporal coding. Cereb. Cortex. 9:484-496, 1999.

Mosher JC, Lewis PS, Leahy RM. Multiple dipole modeling and localization from spatiotemporal MEG data. IEEE Trans. Biomed. Eng. 39:541-557, 1992.

Mossop JE, Wilson MJ, Caspary DM, Moore DR. Down-regulation of inhibition following unilateral deafening. Hear. Res. 147:183-187, 2000.

Nätänen R, Picton T. The N1 wave of the human electric and magnetic response to sound: A review and an analysis of the component structure. Psychophysiology 24:375-425, 1987.

Nalcaci E, Basar-Eroglu C, Stadler M. Visual evoked potential interhemispheric transfer time in different frequency bands. Clin. Neurophysiol. 110:71-81, 1999.

Ponton CW, Don M, Waring MD, EgGermont JJ, Masuda A. Spatiotemporal source modeling of evoked potentials to acoustic and cochlear implant stimulation. Electroencephalogr. Clin. Neurophysiol. 88:478-493, 1993.

Ponton CW, Don M, Eggermont JJ, Waring MD, Masuda A. Maturation of human cortical auditory function: Differences between normal hearing and cochlear implant children. Ear 17:430-437, 1996a.

Ponton CW, Don M, Eggermont JJ, Waring MD, Kwong B, Masuda A. Auditory system plasticity in children after long periods of complete deafness. Neur report. 8:61-65, 1996b.

Ponton CW, Moore JK, Eggermont JJ. Prolonged deafness limits auditory system developmental plasticity: evidence from an evoked potential study in children with cochlear implants. Scand. Audiol. Suppl. 51:13-22, 1999.

Ponton CW, Eggermont JJ, Don M, Waring MD, Kwong B, CunnINGHAM J, TRAUTWEIN P. Maturation of the mismatch negativity: effects of profound deafness and cochlear implant use. Audiol. Neurotol. 5:167-185, 2000.

Ponton CW, Vasama JP, Tremblay K, Khosla D, Kwong B, Don M. Plasticity in the adult human central auditory system: evidence from late-onset profound unilateral deafness. Hear. Res. 154:32-44, 2001.

Ponton CW, Eggermont JJ, Khosla D, Kwong B, Don M. Maturation of human central auditory system activity: separating auditory evoked potentials by dipole source modeling. Clin. Neurophysiol. 113:407-420, 2002.

Popelár J, Eire JP, Aran JM, Cazals Y. Plastic changes in ipsi-contralateral differences of auditory cortex and inferior colliculus evoked potentials after injury to one ear in the adult guinea pig. Hear. Res. 72:125-134, 1994.

Rajan R, Irvine DR, Wise LZ, Heil P. Effect of unilateral partial cochlear lesions in adult cats on the representation of lesioned and unlesioned cochleas in primary auditory cortex. J. Comp. Neurol. 338:17-49, 1993.

Reale RA, Brugge JF, Chan JC. Maps of auditory cortex in cats reared after unilateral cochlear ablation in the neonatal period. Brain Res. 192:281-290, 1987.

Reser DH, Fishman YI, Arezzo JC, Steinschneider M. Binaural interactions in primary auditory cortex of the awake macaque. Cereb. Cortex. 10:574-584, 2000.

Robertson D, Irvine DR. Plasticity of frequency organization in auditory cortex of guinea pigs with partial unilateral deafness. J. Comp. Neurol. 282:456-471, 1989. 
Scheffler K, Bilecen N, Tschopp K, Seelig J. Auditory cortical responses in hearing subjects and unilateral deaf patients as detected by functional magnetic resonance imaging. Cereb. Cortex. 8:156-163, 1998.

Scherg M, Von Cramon D. Two bilateral sources of late AEP as identified by a spatiotemporal dipole model. Electroencephalogr. Clin. Neurophysiol. 62:32-44, 1985.

Scherg M, Von Cramon D. Evoked dipole source potentials of the human auditory cortex. Electroencephalogr. Clin. Neurophysiol. 65:344-360, 1986.

SCHERG M. Functional imaging and localization of electromagnetic brain activity. Brain Topogr. 5:103-111, 1992.

SNYDER AZ. Dipole source localization in the study of EP generators: A critique. Electroencephalogr. Clin. Neurophysiol. 80:321-325, 1991.

Steinschneider M, Volkov IO, Noh MD, Garell PC, Howard MA. Temporal encoding of the voice onset time phonetic parameter by field potentials recorded directly from human auditory cortex. J. Neurophysiol. 82:2346-2357, 1999.

Suga N, Gao E, Zhang Y, Ma X, Olsen JF. The corticofugal system for hearing: recent progress. Proc. Natl. Acad. Sci. U.S.A. 97:11807-11814, 2000.
Tonnquist-Uhlen I, Ponton CW, Eggermont JJ, Kwong B, Don M. Maturation of human central auditory system activity: The T-complex. Clin. Neurophysiol. (in press).

VASAMA J-P, MÄKELÄ JP. Auditory pathway plasticity in adult humans after unilateral idiopathic sudden sensorineural hearing loss. Hear. Res. 87:132-140, 1995.

VASAMA J-P, MäKelä JP. Auditory cortical responses in humans with profound unilateral sensorineural hearing loss from early childhood. Hear. Res. 104:183-190, 1997.

Vasama J-P, Mäkelä JP, Pyykkö I, Hari R. Abrupt unilateral deafness modifies function of human central auditory pathways. Neuro report. 6:961-964, 1995.

Vasama J-P, Mäkelä JP, Ramsay H. Modification of auditory pathway functions in patients with hearing improvements after middle ear surgery. Otolaryngol. Head Neck Surg. 119:125-130, 1998.

Verkindt C, Bertrand O, Thevenet M, Pernier J. Two auditory components in the 130-230 ms range disclosed by their stimulus frequency dependence. Neuro report. 5:1189-1192, 1994.

Zatorre RJ, Evans AC, Meyer E, GJedde A. Lateralization of phonetic and pitch discrimination in speech processing. Science. 256:846-849, 1992. 